\title{
Patient characteristics of hypoglycemia in type 2 diabetes mellitus in China: a retrospective cohort study and data analysis
}

\section{yongwen zhang ( $\sim 651543010 @ q q . c o m)$}

Nanjing Integrated Traditional Chinese and Western Medicine Hospital Affiliated with Nanjing University of Chinese Medicine https://orcid.org/0000-0001-5399-9178

Huanhuan Han

Nanjing Integrated Traditionl Chinese and we

Lanfang Chu

General Hospital of Eastern Military Area

Research article

Keywords: Hypoglycemia, Retrospective study, Rate of hypoglycemia, Cognitive dysfunction

Posted Date: July 9th, 2019

DOI: https://doi.org/10.21203/rs.2.11116/v1

License: (c) (i) This work is licensed under a Creative Commons Attribution 4.0 International License. Read Full License 


\section{Abstract}

Background: The goals of the present study were to quantify incidence rate of hypoglycemia, in-vestigate risk factors for hypoglycemia in patients with type 2 diabetes mellitus (T2DM) and suggest preventive measures. Methods: This study was a retrospective cohort, multicenter, non-interventional study of hypogly-cemic events, used previously acquired data from 10,359 patients with T2DM, who were treated between March 2015 and March 2018. Two aspects of our research were investigated: (i) retrospec-tive study to assess the incidence of hypoglycemia during hospitalization; and (ii) to determine the relationship between hypoglycemia and risk factors such as age, $\mathrm{HbA} 1 \mathrm{c}$, complications, duration of DM, insulin and/or SU use, and cognitive impairment. Results: Overall, 9,993 patients were included in the full analysis set, 376 patients were identified hypoglycemia in the database. Demographic characteristics of patients with T2DM were similar between hypoglycemia and non-hypoglycemia groups, significant differences were not observed between the groups, except for cognitive impairment ( $p=0.037)$. The most common cause of hypo-glycemia was drug overdose/misuse (34.2\%), irregular diet (21.3\%), and excessive physical activity (13.8\%). Most of the hypoglycemic episodes occurred before and after lunch (39.4\% between 10:00 and 13:00). Retrospective rates (events per patient per month [PPPM]) of overall, severe, and noc-turnal hypoglycemia were 3.83 events PPPM (95\% $\mathrm{Cl} 1.90-5.80), 1.17$ events PPPM (95\% $\mathrm{Cl} 0.78-1.56)$, and 0.07 events PPPM (95\% $\mathrm{Cl} 0.05-0.09)$. Multivariate model analysis showed that the use of $\mathrm{SU}(\mathrm{OR}=3.162, \mathrm{p}=0.040)$ and insulin $(\mathrm{OR}=2.414, \mathrm{p}=0.017)$ were associated with hypo-glycemic events. Logistic regression analysis of the variables revealed that significant positive as-sociation of the frequency of overall and severe hypoglycemia with age (beta $=0.855, p=0.018$; be-ta $=1.343, p=0.015)$ and duration of DM (beta $=1.248, p=0.025$; beta $=0.947, p=0.014)$. Conclusions: The present study shows that advanced age, duration of DM, cognitive dysfunction, and insulin and/or SU use are the main causes of hypoglycemia in Chinese patients with T2DM. Education on hypoglycemia, appropriate use of antidiabetic drugs and avoidance of related risk factors are essential for patients with DM.

\section{Background}

Hypoglycemia, especially fear of hypoglycemia, constitutes an important obstacle to glycemic control with antihyperglycemic agents (AHAs). Hypoglycemia may be fatal in type 2 diabetes mellitus(T2DM) and more patients died in the intensive glycemic therapy group in Action to Control Cardiovascular Risk in Diabetes(ACCORD)[1-2]. Recent reports indicated that $6-10 \%$ of deaths of patients with T1DM were caused by hypoglycemia[3-4]. Mortality due to hypoglycemia in patients with T2DM remains unclear. The American Diabetes Association(ADA) Workgroup recommended that if the self-monitoring plasma glucose level of patients with DM is $3.9 \mathrm{mmol} / \mathrm{L}(70 \mathrm{mg} / \mathrm{dL})$ or lower, attention should be paid to the possibility of hypoglycemia[5]. The recommended glucose alert concentration of $3.9 \mathrm{mmol} / \mathrm{L}$ or lower is data driven, it gives the patients and physicians time to take action to prevent hypoglycemic, at the same time, it also provides some margin for the limited accuracy of blood glucose meters at the hypoglycemic levels[1]. Although some physicians argued that the alert value of glucose is slightly lower, there is little disagreement on this apparently controversial issue[6]. 
The recent Global Attitude of Patients and Physicians (GAPP2) study revealed that nearly a quarter of patients with T2DM intentionally reduce or miss the dosage of AHAs because they are aware of the risk of hypoglycemia[7]. Recent guidelines for DM treatment recommend personalized targets that seeking balance to achieve good glucose control without or little hypoglycemia[8]. Randomized controlled trials (RCTs) are still the most common source of data and are the gold standard to prove the clinical safety and efficacy of AHAs[9]. Recent comparison of real-world data (RWD) and RCTs data in DM populations revealed that hypoglycemia is more common in the real-world settings than in clinical trial settings[10]. These conclusions further indicate that it is necessary to determine the true incidence of hypoglycemia in clinical practice.

For patients with DM, it is very important to prevent the occurrence of hypoglycemia in daily life, especially those with related complications and chronic DM, they are more likely to develop asymptomatic hypoglycemia. Severe hypoglycemia not only impairs the cognitive function of patients, but also leads to stroke, cardiovascular events, traumatic falls and even death. Especially, the susceptibility of elderly patients to hypoglycemia increased significantly. Therefore, avoiding hypoglycemia is an important consideration when setting glycemic goals and choosing therapeutic agents[11]. However, few studies have investigated the clinical causes of hypoglycemia and relationship between hypoglycemia, type of treatment and risk factors in patients with T2DM. Since hypoglycemia is a significant risk factor for dementia, treatment medications and goals should be determined according to the demographic data of patients, such as age, cognitive function, comorbidities and activities of daily life. So far, few epidemiological studies have been conducted on the incidence of hypoglycemia in Chinese patients with T2DM. The goals of the present study were to quantify incidence rate of hypoglycemia, investigate risk factors for hypoglycemia in patients with T2DM and suggest preventive measures.

\section{Subjects}

\subsection{Study population}

The present retrospective cohort study used data previously obtained from 10,359 patients with T2DM, who were treated at Nanjing Integrated Traditional Chinese and Western Medicine Hospital and General Hospital of Eastern Military Area between March 2015 and March 2018. We collected the following clinical data: age, sex, type of diabetic treatment, body mass index (BMI), causes of hypoglycemia, and $\mathrm{HbA} 1 \mathrm{c}$ levels. Eligible patients had a diagnosis of T2DM and were aged $>18$ years. We further excluded patients with polycystic ovarian syndrome or gestational diabetes, or those who were pregnant during study. We excluded 236 patients with incomplete demographic, leaving 9,993 individuals. The study was approved by the ethics committee of the Nanjing integrated traditional Chinese and western medicine hospital affiliated with Nanjing university of Chinese medicine.

\subsection{Sensitivity Analyses}


In order to explore the potential mediating roles of specific variables and effect of design we conducted a series of sensitivity analyses. First, we adjusted for patterns of AHAs, the occurrence of a hypoglycemic event, and changes of $\mathrm{HbA} 1 \mathrm{c}$ during study by rerunning Cox proportional hazards model, these variables are not only baseline covariates, but also time-dependent covariates. Second, we limited our analysis to only the linked study cohort to measure the relationship between risk factors and hypoglycemic. Third, we used marginal structural models to adjust the potential time-varying confounding factors affected by therapeutic regimen as an exploratory analysis to explore the effect of AHAs on overall hypoglycemic. Fourth, because metformin may be used to treat prediabetes and other diseases, we conducted a sensitivity analysis, excluded 130 patients who were treated solely on the basis of metformin.

\section{Methods}

\subsection{Study design}

This study was a retrospective cohort, multicenter, non-interventional study of hypoglycemic events. Two aspects of our research were investigated: (i) retrospective study to assess the incidence of hypoglycemia during hospitalization; and (ii) to determine the relationship between hypoglycemia and risk factors such as age, HbA1c, complications, duration of DM, insulin and/or SU use, and cognitive impairment.

\subsection{Data Source}

We retrospectively analyzed the data of the Huayi Blood Glucose Online Monitoring System, a hospitalbased composite database established by Huayi Medical Data Co., Ltd, this database contains anonymous information in hospital electronic records since April 2014. Our study received approval from the ethics committees of both hospitals.

\subsection{Outcomes}

The primary outcome of the study was the percentage of patients who experienced at least one hypoglycemic event during the hospitalization. Secondary outcomes included the differences in the incidence of overall, severe and nocturnal hypoglycemia; the relationship between hypoglycemic events and treatment; and the association between hypoglycemia and risk factors. We compared treatment agents, risk factors, BMI, age, and data between patients with and without hypoglycemia.

\subsection{Hypoglycemia classification}

Categories of hypoglycemia included any hypoglycemia (the sum of non-severe hypoglycemia and severe hypoglycemia), severe hypoglycemia (any hypoglycemic event requiring assistance of another person to 
administer glucagon, carbohydrate or other resuscitative actions), and nocturnal hypoglycemia (any event occurring between midnight and 06:00 am)[5].

\subsection{Statistical analyses}

The percentage of patients with at least one hypoglycemic event and $95 \% \mathrm{Cl}$ for this percentage were calculated, assuming a binomial distribution. Patients in the control group were randomly selected from inpatients whose index date was within the same time as the case patients' index date. Odds ratios for hypoglycemia were assessed in association with predefined factors: age, BMI, duration of DM, the number of daily insulin injections, insulin dose, $\mathrm{HbA1c}$, and AHAs. For the baseline variables, summary statistics were calculated using frequencies for categorical data, and the means and standard deviations for continuous variables. When comparing the hypoglycemic group with the non-hypoglycemic group, Welch's t-test was used for continuous variables, and Pearson's $\chi^{2}$-test was used for binary variables. Multivariable logistic regression was used to examine the risk-adjusted probabilities of treatment and hypoglycemia, respectively. Covariates included insulin use, age, baseline BMI, duration of DM, and baseline A1C. A two-sided P-value of $<0.05$ was considered to be statistically significant, and all statistical analyses were carried out using the Statistical Product and Service Solutions 22.0 software.

\section{Results}

\subsection{Patient characteristics}

Overall, 9,993 patients were included in the full analysis set, 376 patients were identified hypoglycemia in the database. Table 1 shows characteristics in hypoglycemic patients compared with the control nonhypoglycemic group. The average ages of patients and controls were $52.0 \pm 12.5$ and $48.3 \pm 14.4$ years, the average $\mathrm{HbA} 1 \mathrm{c}$ levels were $69.1 \pm 15.3 \mathrm{mmol} / \mathrm{mol}(8.5 \pm 1.4 \%)$ and $62.4 \pm 10.4 \mathrm{mmol} / \mathrm{mol}(7.9 \pm 0.9 \%)$, the DM durations were $9.7 \pm 7.6$ and $11.3 \pm 7.0$ years, the number of daily insulin injections were $2.2 \pm 1.0$ and $2.3 \pm 1.2$, respectively (Table 1).Demographic characteristics of patients with T2DM were similar between hypoglycemia and non-hypoglycemia groups, significant differences were not observed between the groups, except for cognitive impairment $(p=0.037)$.

\subsection{Causes of hypoglycemia}

Causes of hypoglycemia in our study including drug overdose/misuse, irregular diet, excessive physical activity, reduce food intake, liver or kidney dysfunction, drinking, advance age, malnutrition, brittle diabetic, and somogy phenomenon. Factors considered to cause hypoglycemia were described in Figure 1(A). The most common cause of hypoglycemia was drug overdose/misuse (34.2\%), the second most common trigger was irregular diet (21.3\%), the third was excessive physical activity (13.8\%). The author's study also demonstrated that $37.2 \%$ of patients with hypoglycemia were caused by insulin use, 
approximately $19.4 \%$ of patients with hypoglycemia were due to the combined use of insulin and SU, $12.2 \%$ of patients with hypoglycemia were caused by the use of SU (Figure 1B).

\subsection{Time of occurrence of hypoglycemia}

Time of occurrence of hypoglycemia with blood glucose level $<3.9 \mathrm{mmol} / \mathrm{L}$ was show in Figure 2. In our study, most of the hypoglycemic episodes occurred before and after lunch (39.4\% between 10:00 and 13:00).

\subsection{Frequency of hypoglycemia}

Retrospective rates (events per patient per month [PPPM]) of overall, severe, and nocturnal hypoglycemia were 3.83 events PPPM (95\% Cl 1.90-5.80), 1.17 events PPPM (95\% Cl 0.78-1.56), and 0.07 events PPPM (95\% $\mathrm{Cl} 0.05-0.09)$. The rates of patients experienced at least 2-3 hypoglycemic and severe hypoglycemic events were 0.06 events PPPM (95\% $\mathrm{Cl} 0.04-0.08)$ and 0.05 events PPPM (95\% Cl: $0.03-0.07)$, respectively(Table.2).

\subsection{Hypoglycemia risk by drug class}

Multivariate model analysis showed that the use of SU and insulin were associated with hypoglycemic events. Hypoglycemic events increased in patients treated with insulin and SU compared with those treated with other AHAs, with ORs of 2.414 (Cl: 1.174-4.964, $p=0.017)$ and 3.162 (95\% Cl: 1.056-9.471, $p$ $=0.040$ ), respectively (Table 3).

\subsection{Logistic regression analysis}

In univariate analysis, we performed a logistic regression analysis of variables associated with hypoglycemia, revealed a significant positive association of the frequency of overall and severe hypoglycemia with age (beta $=0.855, p=0.018$; beta $=1.343, p=0.015)$ and duration of DM (beta $=1.248$, $p=0.025$; beta $=0.947, p=0.014$ ) (Table 4). The association with other variables seen on univariate analysis did not achieve significance during regression analysis. In regard to different therapeutic regimens, there was no statistically significant difference in hypoglycemia when comparing different regimens for patents with T2DM, except for insulin use for overall hypoglycemia (beta=1.194, $p=0.031$ ).

\section{Discussion}

Although strict control of glycemic may be beneficial for some patients with DM, achieving a level of $\mathrm{HbA1c}$ less than $53 \mathrm{mmol} / \mathrm{mol}(7.0 \%)$ may increase risk of hypoglycemia[12-13]. In particular, patients with advanced age, limited life expectancy, and complex health problems are unlikely to benefit from 
strict glycemic control and are more likely to be harmed by it than healthier, younger patients[14-17]. Therefore, the American Geriatrics Society (AGS) Choosing Wisely initiative recommend that drugs other than metformin should not be used to achieve the majority of patients with HbA1c levels less than $58 \mathrm{mmol} / \mathrm{mol}(7.5 \%)$, because of the risk of hypoglycemia and other hazards, including mortality[18]. These recommendations are consistent with other clinical guidelines to promote individualized evidencebased diabetes care, although not explicitly stated[19].

This multicenter, non-interventional and retrospective study investigated the prevalence of hypoglycemia in patients with T2DM in China. We report rates of overall (3.83 events PPPM), nocturnal (1.17 events PPPM), and severe (0.07 events PPPM) hypoglycemia in patients with T2DM that are higher than previously reported in RCTs such as ACCORD (0.11 events PPPM) and real-world epidemiological studies such as the VADT and PREDICTIVE trials (0.26-1.11events PPPM) [20-22]. These studies suggest that the incidence rates of hypoglycemia are affected by many factors, including the characteristics of the patients and the definition of hypoglycemia in the study. Because the present study included patients visiting our hospitals, it is speculated that patients in our study have accumulated more severe complications than the general patients with T2DM. Even with the higher incidence rate, there is a possibility that the rate was underestimated in this study because hypoglycemic events cannot be captured when patients are treated in other hospitals.

Determining the risk factors of hypoglycemia is helpful for patients and physicians to optimize glycemic control and select appropriate antidiabetic drugs. The present study shows that advanced age, duration of DM, cognitive impairment, and insulin and/or SU use, are the main factors leading to hypoglycemia. As the number of elderly patients with advanced T2DM increase, people with T2DM accompanied by cognitive impairment become increase [23]. To prevent hypoglycemia, it is necessary to have a intact cognitive function to regulate dietary patterns and activity levels, identify symptoms and responsiveness related with glycemic levels, predict the occurrence of hypoglycemia, and initiate appropriate mitigation actions[24-25]. Cognitive impairment promotes irrational and erratic behavior, causes confusion and affects balance and vision, which can lead to accidents and falls, and sometimes has more serious neurological consequences. Our retrospective study showed that the risk of hypoglycemia in patients with cognitive impairment at baseline was significantly higher than those who did not have cognitive dysfunction. Cognitive function should be assessed when managing patients with $D M$, and for patients with low cognitive function, physicians should pay attention to the patients to prevent hypoglycemia. Our study suggested that advanced age and duration of DM were evaluated as risk factors for hypoglycemia. Age and the duration of DM are probably important predictors for development of hypoglycemia in patients with T2DM. These results suggested that with progression of $\beta$-cell failure, the increased risk of hypoglycemia in patients with long duration of T2DM is progressively similar to those with T1DM. In our study, 3,570 hypoglycemic episodes were detected using a hospital-based database. The correlation between hypoglycemia and AHAs use was shown in table 3. The ORs of hypoglycemia were higher in patients with insulin(OR=2.414, 95\% Cl: 1.174-4.964) , SU(OR=3.162, 95\% Cl: 1.056-9.471), a-GI(OR=2.297, $95 \% \mathrm{Cl}: 0.870-6.062)$, and glinide (OR=2.882, 95\% Cl: 0.959-8.663), the ORs of hypoglycemia were lower in patients with DPP-4 inhibitor(OR=0.795, 95\% Cl: 0.398-1.588) and SGLT-2 inhibitor (OR=0.725, 95\%Cl: 
0.058-8.987). On multiple regression analysis, insulin and SU showed a strong association with hypoglycemia.

In this study, although $\mathrm{HbA} 1 \mathrm{c}$ is a good indicator of blood glucose control, there is no correlation between the presence of hypoglycemia and HbA1c level in patients with T2DM. Therefore, it is difficult to forecast the occurrence of hypoglycemia in patients with T2DM by detecting $\mathrm{HbA} 1 \mathrm{c}$ alone. Many physicians believe that the risk of hypoglycemia is negatively correlated with $\mathrm{HbA} 1 \mathrm{c}$ levels, mainly based on the Diabetes Control and Complications Trial(DCCT) evidence [26]. However, recent studies have failed to confirm the relationship between hypoglycemia and $\mathrm{HbA} 1 \mathrm{c}$, suggesting that hypoglycemia is common at all glycemic control levels, and our study also supports this point [27-29].

Most of the hypoglycemic episodes occurred before and after lunch (39.4\% between 10:00 and 13:00) (Figure 2). Among hypoglycemic patients, the majority of the patients treated with SUs (42.3\%). The observed time of occurrence of hypoglycemic may be explained by the pharmacodynamic and pharmacokinetic characteristics of $\mathrm{SU}$, the peak plasma concentration (tmax) of SU is 2-4 hours, which is consistent with the peak of appearance of hypoglycemia in the late morning. However, other factors including excessive physical activity and lunch delay are highly likely to associate with the appearance of hypoglycemia before and after lunch.

Reducing the risk factors of hypoglycemia is an empirical method to minimize the risk of hypoglycemia while improving or maintaining glycemic control in patients with DM. It includes three steps: apply the principles of aggressive glycemic therapy; acknowledge the problem and consider the conventional risk factors[30,31]. Patient education and empowerment are fundamentally important. Improving patient knowledge of hypoglycemia and educating them to use insulin and glucose-monitoring equipment correctly are important methods to reduce the occurrence of hypoglycemia. Active glycemic treatment principles include diabetes self-management, appropriate and flexible insulin and other drugs, frequent self-monitoring of blood glucose levels, ongoing professional support and guidance, and individualized glycemic goals[1]. Ideally, patients should monitor glucose level when suspecting hypoglycemia. That would refute or confirm an episode and might lead to adjustments of regimen and help the patients understand their individual symptoms. Severe hypoglycemic episodes are clinical red flag. Unless the cause is easily remediable, radical changes in therapeutic regimens should be considered immediately. Without such adjustment, the risk of subsequent severe hypoglycemia would be high[32-33]. Patients need to understand the traditional risk factors associated with hypoglycemia, including the insulin preparations or temporal patterns of the glucose-lowering actions of their individual secretagogue, and the effects of exercise, the overnight fast, missed meals, and alcohol intake. Patients need to learn to apply their self-monitoring of blood glucose data toward the goal of minimizing hypoglycemia. Late postexercise hypoglycemia, nocturnal hypoglycemia, or both should prompt appropriate timing adjustments to provide less insulin action, more carbohydrate intake, or both. Caregivers should educate patients with DM to be alert to hypoglycemia before and after lunch, eating lunch on time, avoid excessive exercise before lunch, and monitor blood glucose when necessary. Because the management of DM is empirical, 
physicians should work with each patient to find the safest and most effective treatment at a specific point in the course of that patient's diabetes.

The present study had some limitations. First, the database may reflect the more unhealthy T2DM population. Second, the database is a composite database based on hospital inpatients, so this study has the essential limitations of hospital research. Third, the results of this study were based on measurements of interstitial fluid glucose levels, not blood sugar levels. Fourth, frequent episodes of severe hypoglycemia can affect patient's mental performance, functional status, and risk of falls, these important results cannot be evaluated because this is a retrospective study. Finally, our study is retrospective, so a prospective study is being planned.

\section{Conclusions}

The present study shows that advanced age, duration of DM, cognitive dysfunction, and insulin and/or SU use are the main causes of hypoglycemia in Chinese patients with T2DM. These findings support treatment guidance for patients with T2DM in whom glycemic control objectives are determined according to health status and drug types in order to avoid hypoglycemic. The current study remains an exploratory analysis, and further studies are needed to assess the incidence of hypoglycemia in outpatients with T2DM and confirm these findings. The results also indicate that education on hypoglycemia, appropriate use of antidiabetic drugs and avoidance of related risk factors are essential for patients with DM. It is hoped that these results will aid physician better tailor treatment options for patients with DM, especially in areas where data from such studies have not previously been available.

\section{Abbreviations}

T2DM: Type 2 diabetes mellitus PPPM: Per patient per month AHAs: Antihyperglycemic agents ACCORD: Action to Control Cardiovascular Risk in Diabetes ADA: American Diabetes Association GAPP2:Global Attitude of Patients and Physicians RCTs: Randomized controlled trials RWD: Real-world data BMI: Body mass index Cl: Confidence Interval MDI: multiple daily injections CHD: Coronary Heart Disease AMI: Acute myocardial infarction SU: sulfonylurea a-Gl: a-glycosidase inhibitors DPP-4 inhibitor: dipeptidyl peptidase4 inhibitors SGLT-2: sodium-glucose cotransporter-2 inhibitors. AGS: American Geriatrics Society DCCT: Diabetes Control and Complications Trial.

\section{Declarations}

Ethics approval and consent to participate The study was approved by the ethics committee of the Nanjing integrated traditional Chinese and western medicine hospital affiliated with Nanjing university of Chinese medicine. The committee also approved the present study with the approval number 2015/002. All participants gave written informed consent for medical research and to have their data linked to other registers or surveys. 
Consent for publication Not applicable.

Availability of data and material Data are available. Please contact corresponding author.

Competing interests None of the authors have any potential conflicts of interest associated with this research.

Funding This research received no specific grant from any funding agency in the public, commercial or not-for-profit sectors.

Authors' contributions ZYW conceptualized the study, analyzed the data and wrote the article. $\mathrm{HHH}$ and CLF contributed to the interpretation of the results. All authors read and approved the final manuscript.

Acknowledgements Not applicable.

\section{References}

1. Phlilp E. Cryer. Hypoglycemia. in: Melmed S, Polonsky KS, Larsen PR, et al. eds. Williams Textbook of Endocrinology,12th ed. Philadelphia, PA: Saunders; 2011:1552-1577.

2. Holstein A, Egberts EH. Risk of hypoglycaemia with oral antidiabetic agents in patients with type 2 diabetes. Exp Clin Endocrinol Diabetes 2003;111:405-414.

3. Diabetes Control and Complications Trial/Epidemiology of Diabetes Interventions and Complications Study Research Group, Jacobson AM, Musen G. Long-term effect of diabetes and its treatment on cognitive function. N Engl J Med 2007;356:1842-1852.

4.Feltbower RG, Bodansky HJ, Patterson CC, et al. Acute complications and drug misuse are important causes of death for children and young adults with type 1 diabetes: results from the Yorkshire Register of diabetes in children and young adults. Diabetes Care 2008;31:922-926.

5. Workgroup on Hypoglycemia, American Diabetes Association. Defining and reporting hypoglycemia in diabetes : a report from the American Diabetes Association Workgroup on Hypoglycemia. Diabetes Care 2005;28: 1245-1249.

6. Cryer PE. Preventing hypoglycaemia: what is the appropriate glucose alert value? Diabetologia 2009;52:35-37.

7. Leiter LA, Boras D, Woo VC. Dosing irregularities and self-treated hypoglycemia in type 2 diabetes: results from the Canadian cohort of an international survey of patients and healthcare professionals. Can J Diabetes 2014;38:38-44.

8. Inzucchi SE, Bergenstal RM, Buse JB, et al. Management of hyperglycemia in type 2 diabetes, 2015: a patient-centered approach: update to a position statement of the American Diabetes Association and the 
European Association for the Study of Diabetes. Diabetes Care 2015;38:140-149.

9. Emral R, Pathan F, Cortés CAY , et al. Self-reported hypoglycemia in insulin-treated patients with diabetes: Results from an international survey on 7289 patients from nine countries. Diabetes Res Clin Pract 2017;134:17-28

10. Elliott L, Fidler C, Ditchfield A, et al. Hypoglycemia event rates: a comparison between real-world data and randomized controlled trial populations in insulin-treated diabetes. Diabetes Ther 2016;7:45-60.

11. Geller Al, Shehab N, Lovegrove MC, et al. National estimates of insulin-related hypoglycemia and errors leading to emergency department visits and hospitalizations. JAMA Intern Med 2014; 174: 678686.

12. Bonds DE, Miller ME, Bergenstal RM, et al. The association between symptomatic, severe hypoglycaemia and mortality in type 2 diabetes: retrospective epidemiological analysis of the ACCORD study. BMJ. 2010; 340:b4909.

13. Zoungas S, Patel A, Chalmers J, et al. ADVANCE Collaborative Group. Severe hypoglycemia and risks of vascular events and death. N Engl J Med 2010; 363:1410-1418.

14.Duckworth WC, Abraira C, Moritz TE, et al. Investigators of the VADT. The duration of diabetes affects the response to intensive glucose control in type 2 subjects: the VA Diabetes Trial. J Diabetes Complications $2011 ; 25: 355-361$.

15.Huang ES, Laiteerapong N, Liu JY, et al . Rates of complications and mortality in older patients with diabetes mellitus: the diabetes and aging study. JAMA Intern Med 2014; 174:251-258. 16.Vijan S, Sussman JB, Yudkin JS, et al. Effect of patients' risks and preferences on health gains with plasma glucose level lowering in type 2 diabetes mellitus. JAMA Intern Med 2014; 174:1227-1234.

17.Ikeda Y, Kubo T, Oda E, et al. Incidence rate and patient characteristics of severe hypoglycemia in treated type 2 diabetes mellitus patients in japan: Retrospective Diagnosis Procedure Combination analysis. J Diabetes Investig. 2018; 9:925-936

18. AGS Choosing Wisely Workgroup. American Geriatrics Society identifies another five things that healthcare providers and patients should question. J Am Geriatr Soc 2014; 62:950-960.

19. Kirkman MS, Briscoe VJ, Clark N, et al. Consensus Development Conference on Diabetes and Older Adults. Diabetes in older adults: a consensus report. J Am Geriatr Soc 2012; 60:2342-2356.

20. Miller ME, Bonds DE, Gerstein HC, et al. The effects of baseline characteristics, glycaemia treatment approach, and glycated haemoglobin concentration on the risk of severe hypoglycaemia: post hoc epidemiological analysis of the ACCORD study. BMJ 2010;340:b5444. 
21. Dornhorst A, Luddeke HJ, Sreenan S, et al. Safety and efficacy of insulin detemir in clinical practice: 14-week follow-up data from type 1 and type 2 diabetes patients in the PREDICTIVE European cohort. Int J Clin Pract 2007;61:523-528.

22. Duckworth W, Abraira C, Moritz T, et al. Glucose control and vascular complications in veterans with type 2 diabetes. N Engl J Med 2009;360:129-139.

23. de Galan BE, Zoungas S, Chalmers J, et al. ADVANCE Collaborative Group. Cognitive function and risks of cardiovascular disease and hypoglycaemia in patients with type 2 diabetes: the Action in Diabetes and Vascular Disease: Preterax and Diamicron Modified Release Controlled Evaluation (ADVANCE) trial. Diabetologia 2009;52:2328-2336.

24. Cox DJ, Kovatchev B, Koev D, et al. Hypoglycemia anticipation, awareness and treatment training (HAATT) reduces occurrence of severe hypoglycemia among adults with type 1 diabetes mellitus. Int $\mathrm{J}$ Behav Med 2004;11: 212-218.

25. Punthakee Z, Miller ME, Launer LJ, et al. Poor cognitive function and risk of severe hypoglycemia in type 2 diabetes: post hoc epidemiologic analysis of the ACCORD trial. Diabetes Care 2012; 35: 787-793.

26. The Diabetes Control and Complications Trial Research Group, Nathan DM, Genuth S, Lachin J, et al. The effect of intensive treatment of diabetes on the development and progression of long-term complications in insulin-dependent diabetes mellitus. N Engl J Med 1993;329:977-986.

27. Lipska KJ, Warton EM, Huang ES, et al. HbA1c and risk of severe hypoglycemia in type 2 diabetes: the Diabetes and Aging Study. Diabetes Care 2013;36:3535-3542.

28. Emral R, Pathan F, Cortés CAY, et al. Self-reported hypoglycemia in insulin-treated patients with diabetes: Results from an international survey on 7289 patients from nine countries. Diabetes Res Clin Pract. 2017; 134:17-28.

29.Yun JS, Ko SH, Ko SH, et al. Presence of macroalbuminuria predicts severe hypoglycemia in patients with type 2 diabetes: a 10-year follow-up study. Diabetes Care 2013; 36: 1283-1289.

30.Cryer PE, Davis SN, Shamoon H. Hypoglycemia in diabetes. Diabetes Care 2003;26: 1902-1912.

31.Rossetti P, Porcellati F, Bolli GB, et al. Prevention of hypoglycemia while achieving good glycemic control in type 1 diabetes: the role of insulin analogs. Diabetes Care 2008;31:S113-S120.

32.Allen C, LeCaire T, Palta M, et al. Risk factors for frequent and severe hypoglycemia in type 1 diabetes. Diabetes Care 2001;24:1878-1881.

33.Cox DJ, Gonder-Frederick L, Ritterband L, et al. Prediction of severe hypoglycemia. Diabetes Care 2007;30:1370-1373. 


\section{Tables}

Table 1 Baseline characteristics of patients with T2DM participating in the study.

\begin{tabular}{|c|c|c|c|}
\hline Patient characteristics & Hypoglycemia & Non-hypoglycemia & $\begin{array}{c}p \\
\text { value }\end{array}$ \\
\hline Number of patients (\%) & 376 & 376 & - \\
\hline Age (years) & $52.0 \pm 12.5$ & $48.3 \pm 14.4$ & 0.56 \\
\hline Female \% (95\% CI) & $46.5(36.7-56.3)$ & $50.5(40.7-60.3)$ & 0.57 \\
\hline Body Mass Index $(\mathrm{Kg} / \mathrm{m} 2)$ & $26.4 \pm 3.5$ & $26.0 \pm 3.3$ & 0.77 \\
\hline HbA1c mmol/mol (\%) & $\begin{aligned} 69.1 & \pm 15.3(8.5 \\
& \pm 1.4)\end{aligned}$ & $\begin{aligned} 62.4 & \pm 10.4(7.9 \\
& \pm 0.9)\end{aligned}$ & 0.28 \\
\hline DM duration (years) & $9.7 \pm 7.6$ & $11.3 \pm 7.0$ & 0.61 \\
\hline Smoker \% (95\% CI) & $9.6(3.7-15.5)$ & $11.9(6.0-17.8)$ & 0.26 \\
\hline No. of cigarettes/day & $9.2 \pm 6.2$ & $7.2 \pm 6.0$ & 0.43 \\
\hline Alcohol/week (units) & $4.4 \pm 3.3$ & $6.0 \pm 3.2$ & 0.24 \\
\hline Exercise (hours/week) & $7.5 \pm 2.5$ & $8.1 \pm 2.3$ & 0.53 \\
\hline Number of daily insulin injections & $2.2 \pm 1.0$ & $2.3 \pm 1.2$ & 0.86 \\
\hline MDI\% $(95 \%$ CI $)$ & $34.7(24.9-44.5)$ & $40.6(30.8-50.4)$ & 0.38 \\
\hline Insulin pump\% (95\% CI) & $24.8(17.0-32.6)$ & $30.7(20.9-40.5)$ & 0.35 \\
\hline $\begin{array}{l}\text { Therapeutic compliance \% }(95 \% \\
\text { CI) }\end{array}$ & $49.3(39.5-59.1)$ & $52.6(42.8-62.4)$ & 0.31 \\
\hline Systolic Blood Pressure (mmHg) & $132.9 \pm 13.8$ & $126.7 \pm 13.5$ & 0.27 \\
\hline Diastolic Blood Pressure (mmHg) & $79.6 \pm 9.9$ & $81.3 \pm 10.9$ & 0.70 \\
\hline \multicolumn{4}{|c|}{ History of \% (95\% CI) } \\
\hline Cognitive impairment & $40.6(30.8-50.4)$ & 26.7(18.9-34.5) & 0.037 \\
\hline Hypertension & $56.4(46.6-66.2)$ & $51.5(41.7-61.3)$ & 0.48 \\
\hline Stroke & $22.8(15.0-30.6)$ & $18.8(11.0-26.6)$ & 0.49 \\
\hline AMI & $10.9(5.0-16.8)$ & $16.8(9.0-24.6)$ & 0.22 \\
\hline CHD Angina & $19.8(12.0-27.6)$ & $25.7(17.9-33.5)$ & 0.31 \\
\hline Dyslipidemia & $57.4(47.6-67.2)$ & $50.5(40.7-60.3)$ & 0.32 \\
\hline Neuropathy & $17.8(10.0-25.6)$ & $21.8(14.0-29.6)$ & 0.48 \\
\hline Retinopathy & $14.9(7.1-22.7)$ & $18.8(11.0-26.6)$ & 0.45 \\
\hline Nephropathy & $15.8(8.0-23.6)$ & $20.8(13.0-28.6)$ & 0.36 \\
\hline
\end{tabular}

Values are given as mean (SD) unless otherwise specified.CI: Confidence Interval; MDI: multiple daily injections; CHD: Coronary Heart Disease; AMI: Acute myocardial infarction; 
Table 2 Incidence rates of T2DM with hypoglycemia.

\begin{tabular}{|c|c|c|c|c|}
\hline \multirow[t]{2}{*}{ Variables } & \multirow{2}{*}{$\begin{array}{c}\text { No. } \\
\text { patients }\end{array}$} & \multirow{2}{*}{$\begin{array}{c}\text { No. } \\
\text { episodes }\end{array}$} & \multicolumn{2}{|c|}{ Incidence rate (PPPM) } \\
\hline & & & $\begin{array}{c}\text { Point } \\
\text { estimate }\end{array}$ & $95 \%$ CI \\
\hline Jverall hypoglycemic & 376 & 3570 & 3.83 & $(1.90-5.80)$ \\
\hline Severe hypoglycemic & 122 & 1089 & 1.17 & $(0.78-1.56)$ \\
\hline Nocturnal hypoglycemia & 34 & 61 & 0.07 & $(0.05-0.09)$ \\
\hline $\begin{array}{l}\text { 2-3 hypoglycemic episodes during } \\
\text { lospitalization }\end{array}$ & 35 & 57 & 0.06 & $(0.04-0.08)$ \\
\hline $\begin{array}{l}2-3 \text { severe hypoglycemic episodes } \\
\text { luring hospitalization }\end{array}$ & 26 & 49 & 0.05 & $(0.03-0.07)$ \\
\hline \multicolumn{5}{|l|}{ tge (years) } \\
\hline $20-64$ & 267 & 2611 & 2.80 & $(0.80-4.80)$ \\
\hline$\geq 65$ & 109 & 959 & 1.02 & $(0.63-1.41)$ \\
\hline \multicolumn{5}{|l|}{ 亏ex } \\
\hline Male & 193 & 1824 & 1.96 & $(1.57-2.35)$ \\
\hline Female & 183 & 1746 & 1.87 & $(1.48-2.26)$ \\
\hline \multicolumn{5}{|l|}{ AHAs } \\
\hline Insulin & 140 & 1380 & 1.48 & $(1.09-1.87)$ \\
\hline Insulin +SU & 73 & 788 & 0.85 & $(0.65-1.05)$ \\
\hline SU & 46 & 383 & 0.41 & $(0.21-0.61)$ \\
\hline Insulin +Glinides & 27 & 341 & 0.37 & $(0.17-0.57)$ \\
\hline Insulin $+\alpha-G I$ & 23 & 276 & 0.30 & $(0.10-0.50)$ \\
\hline
\end{tabular}

AHAs, Antihyperglycemic agents CI, confidence interval.

Table 3. Hypoglycemia risk by antidiabetic drug. 


\begin{tabular}{ccccc}
\hline AHAs & OR & \multicolumn{2}{c}{$95 \%$ CI } & $p$ values \\
\cline { 3 - 4 } & & Upper & Lower & \\
\hline Insulin & 2.414 & 4.964 & 1.174 & 0.017 \\
DPP-4 inhibitor & 0.795 & 1.588 & 0.398 & 0.516 \\
\hline Metformin & 1.497 & 2.625 & 0.854 & 0.159 \\
\hline$\alpha$-GI & 2.297 & 6.062 & 0.870 & 0.093 \\
\hline SGLT-2 inhibitor & 0.725 & 8.987 & 0.058 & 0.802 \\
\hline SU & 3.162 & 9.471 & 1.056 & 0.040 \\
\hline Glinide & 2.882 & 8.663 & 0.959 & 0.059 \\
\hline
\end{tabular}

Table 4 Multivariate regression analysis using risk factors of hypoglycemia

\begin{tabular}{ccc}
\hline Risk factors & $\begin{array}{c}\text { Overall hypoglycemia } \\
\text { (beta; } p \text { value) }\end{array}$ & $\begin{array}{c}\text { Severe hypoglycemia } \\
\text { (beta; } p \text { value) }\end{array}$ \\
\hline Age (years) & $0.855 ; 0.018$ & $1.343 ; 0.015$ \\
BMI & $-0.201 ; 0.541$ & $-0.320 ; 0.721$ \\
\hline Duration of diabetes & $1.248 ; 0.025$ & $0.947 ; 0.014$ \\
\hline Total insulin dose & $0.839 ; 0.096$ & $0.609 ; 0.171$ \\
\hline Number of daily injections & $-0.183 ; 0.587$ & $-0.038 ; 0.923$ \\
\hline HbA1c & $0.397 ; 0.166$ & $-0.346 ; 0.683$ \\
\hline Insulin use & $1.194 ; 0.031$ & $0.344 ; 0.231$ \\
\hline
\end{tabular}

Figures 

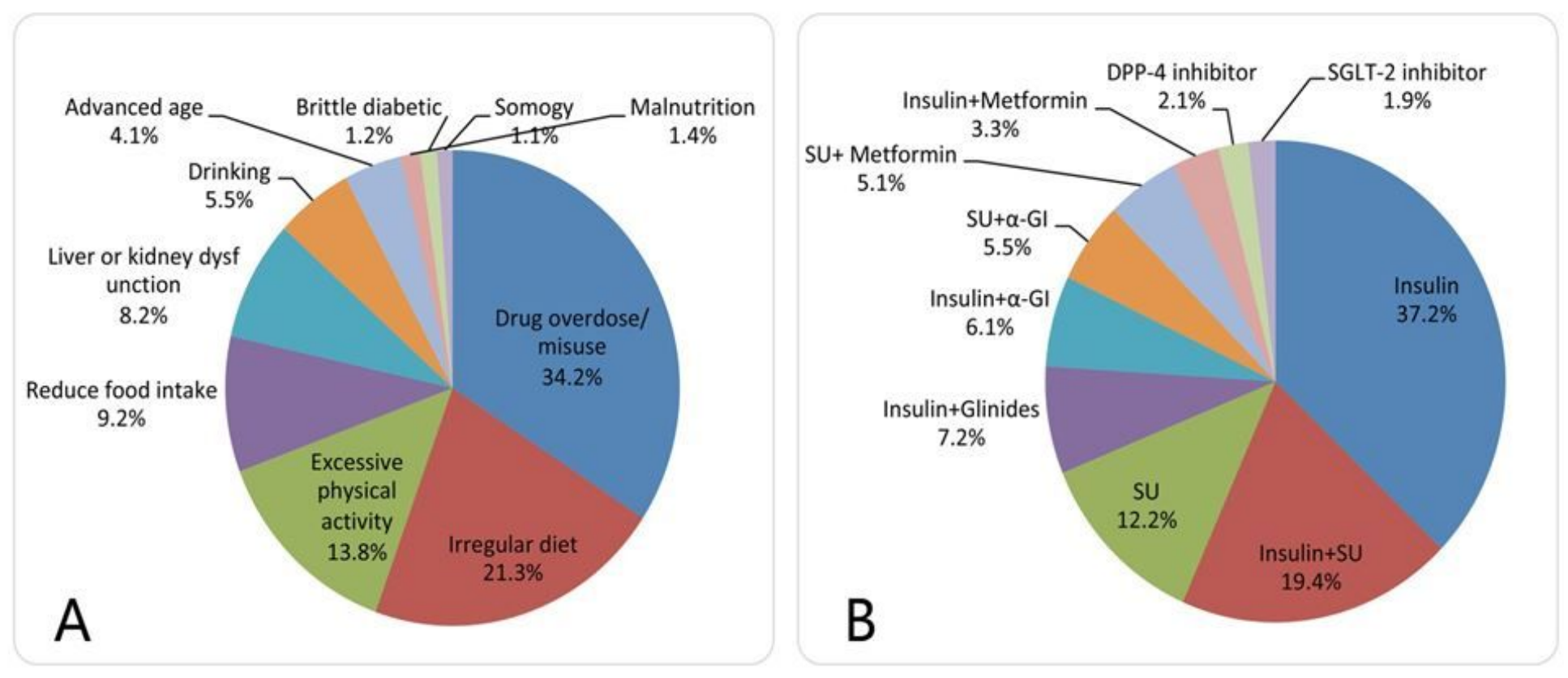

\section{Figure 1}

Causes (A) and causal agents (B) of hypoglycemia in Chinese patients with T2DM. 


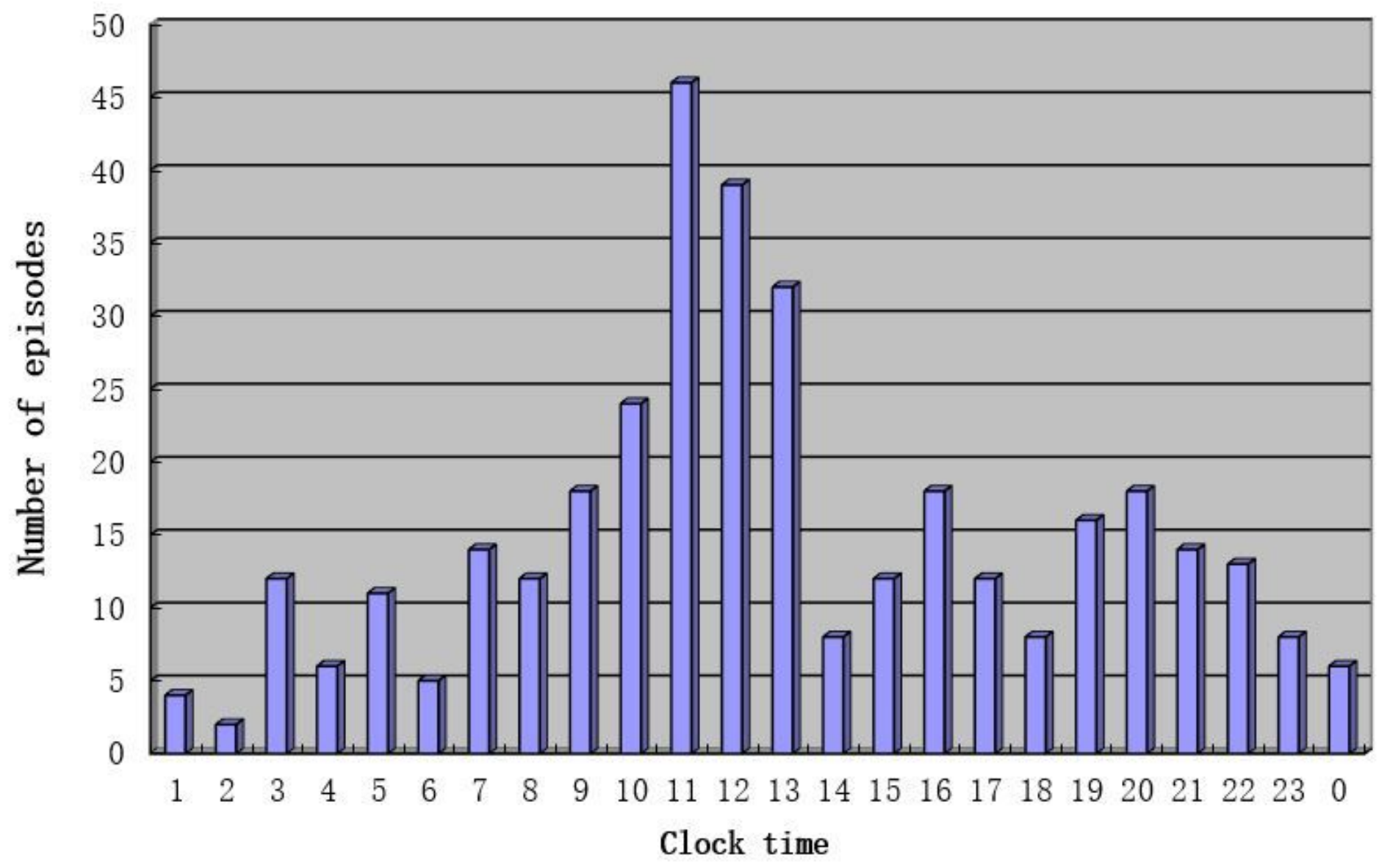

Figure 2

Time of occurrence of hypoglycemia.

\section{Supplementary Files}

This is a list of supplementary files associated with this preprint. Click to download.

- supplement1.doc 